\title{
Ways of Mass Media to Promote Educational Justice on Children from Migrant Worker Families
}

\author{
Jing-Ya WANG ${ }^{1, a,{ }^{*}}$ and Pan $\mathrm{HE}^{2, \mathrm{~b}}$ \\ ${ }^{1} 9-3-804$, No.333, TaiHe 2 Street, Chengdu, Sichuan, China \\ 22-9-2,Xie Li Garden, 30 Wu Hou Avenue, Chengdu, Sichuan, China \\ awestzq@gmail.com, bho.pando@gmail.com, \\ ${ }^{*}$ Corresponding author
}

Keywords: Mass media, Educational Justice, Migrant Children, Migrant Worker Family

\begin{abstract}
This paper demonstrates the policy and family socio-economic status factors impacts on the educational justice on children from the migrant worker families. It explores how the mass media can do to promote the educational justice on migrant children through the lens of Bronfenbrenner's ecological models. It presents that mass media can utilize the social functions including media supervision, agenda setting, and transmission of social heritage to promote the educational justice to migrant children through different ecological systems around them.
\end{abstract}

\section{Introduction}

Educational justice to children from the migrant worker families has been a crucial issue in building harmonious society. It attracts many scholars' attentions to it. Research on this issue mainly comes from the field of education, sociology, economics, and politics. As the growing power of mass media, this paper tries to explore the means of promoting educational justice through the social functions of mass media.

This paper consists of four parts. It begins with the previous studies on educational justice and the status quo in China. Then it presents the social functions of mass media. Followed by the second part, the brief introduction of Bronfenbrenner's ecological model was provided. It used to demonstrate the directions of possible ways to promote educational justice on migrant children. The last part is to explore the ways the mass media can do to promote this issue.

\section{Educational justice}

"Justice" emphasizes a kind of value judgments, which is exploring the rights and fair distributions as well as the ideal design and arrangement for social relationships (Du, 2011). The core issues embedded in the justice is the fair distribution of the benefits. The distributions of benefits for social organizations, groups of peoples, and individuals are isolated from the social class, status, education background, incomes, or regions, which is regarded as the primary rights of citizens. Justice to education is the prerequisite and the foundations for social justice, and it is also one of the important aspects of social justice (Wei, 2011). The notion of educational justice is to ensure each member of the society has the equal opportunity to access to the education recourses and the right to be treated equally in education (Wei, 2011). Zhong (2013) argues that the concept of educational justice was embedded in the fair opportunities for accessing to education, the fair process during education, and the fair results of education. Based on the notion of educational justice, it can be defined as that every school-age child has the right to attend to school and access to the fair education resources as well as receive the equal opportunities in education and the fair education results. 


\section{Status quo of educational justice in China}

Some scholars studied educational justice in China and claimed that children from migrant worker families suffered from the injustice in education which was a new and serious social and educational issue (Long \& Fan, 2014; Cheng, 2013). From the previous studies, the education injustice for the migrant children mainly from the social exclusion (Long \& Wei, 2014). More specifically, the reasons lead education injustice on migrant children were unfair of policies and the gap between socio-economic status of families (Long \& Fan, 2014).

\section{Political factors}

The educational policies, the political structure, and political systems are regarded as the major impediments for migrant children to access the justice education (Cheng, 2013). Because of the household registration system, if migrant children want to receive high quality education, their parents would be required to pay extra expensive fee, named "school building fee" (Cheng, 2013). Actually, however, to those who suffer from the poverty, the migrant worker families cannot afford this extra expensive fee. Therefore most of migrant children were excluded from the national public education system. From the statistics citied in Cheng's research, under the current education policies and politic systems, only $12.5 \%$ of the over 100 thousands of migrant children had attended to school. Other $87.5 \%$ of them were excluded from the education system.

The market mechanisms intervening into the education seriously challenges the educational justice (Liu, 2005). With the market mechanism, the unified examination system aggravates the education injustice. Market mechanisms advocate competition, choice and decentralization, which will lead to a phenomenon of the strong becoming stronger and the weak becoming weaker. In China, students should go through the difficult examinations of the academic knowledge to enter into the higher education. Generally, differences in terms of the resources and school capabilities make the differences between schools. The unified examination, such as college entrance examination, to those who were unable to afford the good quality education, increases their difficulties to further study (Liu, 2007). Due to the limited nature of the overall resource, the fierce competition for resources makes the migrant children be stranded in a more disadvantaged position in education.

\section{Family socio-economic status factors}

Family socio-economic status is another comprehensive factor leading to education injustice. Family socio-economic status brings family members about social and economic resources, which impacts the children's educational ambitions and support or constrain their choices (Liu, 2007). Wang (2005) divided the social status into difference classes and studied the enrollment rates of children from different social classes. He found that the differences of enrollment rates between children from different social classes were huge. The enrolment rates of children from the lower social class families, the migrant worker families, to attend to higher education were significantly lower than the average level of enrolment rates. Supported by Liu (2007), who analyzed the social class stratification and higher education enrolment and found that the family socio-economic status had profound impacts on the educational justice. The enrolment rates of children from the migrant worker families were significantly lower than that from higher social class families. She also found that the children of migrant worker families tended to attend the lower quality school and receive lower quality education. That is, the differences caused by the scope of personal choice can be attributed to the gap of social status. Education injustice caused by the social stratification was argued for the unequal distribution of education resource (Long \& Fan, 2014; Liu, 2007). The unequal distribution of education resource on the migrant children means the insufficient resource to them and the low quality of education they received.

The issue of educational justice on migrant children appeared from the educational democracy has been emphasized and the required by the national education reform and harmonious society. Previous studies exploring educational justice on migrant children focuses on the angle of political 
science, education, economics, sociology, few of them analyze it from the angle of mass media. In order to amend this gap, this paper is to explore the how the mass media can do to promote the social justice on migrant children.

\section{The social functions of the mass communication}

In the studies of mass communication, the social functions of mass communication founded by Lasswell (1948). Lasswell included the mass communication into social systems and social developing process and built the model of "Three Functions". The three functions includes the surveillance of the environment, the correlation of the parts of society in responding to the environment, the transmission of the social heritage from one generation to the next. The surveillance of the environment, which includes media supervision, refers to the media organization utilizing the "news" to keep informing to the society about the changes in the environment, make people be aware of the opportunities or threats which may impact on the social developing process, and objectively and accurately reflect the reality of society. As a social function, it is a basis for decision or action making. The correlation of the parts of society in responding to the environment, known as the "agenda setting", means the mass media links and coordinates the parts of society as a whole through information selection, explanation, and comments. It effects in reacting to the social environment and attracting people's attention to the important issues in current society and avoid the disorder on the environment monitoring. The transmission of the social heritage from one generation to the next, known as the social heritage delivery functions, is about the educational activities of human beings to pass the spiritual heritage, such as social norms and knowledge, through generations. It can foster the formal social value, social norms and social heritage among members in the society to increase the social cohesion. The mass communication is an important mechanism to ensure the social heritage ( $\mathrm{Li}, 2003)$.

Even though many scholars went further to develop other social functions of mass communication (e.g., Schramm, 1987; Lazarsfeld \& Merton, 1949), their findings can be regarded as the development of Lasswell's Three Functions Theory. Indeed, their principles are mutually included. This paper employs Lasswell's Three Functions Theory to identify what the social functions of mass media can be used to promote the educational justice on migrant children. They are the surveillance of the environment (media supervision), the correlation of the parts of society in responding to the environment (agenda setting), the transmission of the social heritage through generations.

\section{The ecological model of human development}

Bronfenbrenner (1984) built the ecological models of human development to present how the environment affects the personal growth. He provided the different levels of systems and explained how a person influenced by the different levels of systems surrounding around. The environment systems divided into four levels: Microsystems, Mesosystems, Exosystems, Marcosystems, and Chronosystems. The ecological environment is conceived as a set of nested structures, works moving from the innermost level to the outside. Microsystem is a pattern of activities, social roles, and interpersonal relations to have face-to-face interactions towards the person. The settings in microsystem include family, school, peer group and workplace. Mesosystem represents the linkages and processes between two or more settings in microsystmes, such as the relationship between home and school. Exosystem builds the linkage between one setting and at least one of the indirect settings having influence on a person's life, for example, the relationship between family and the parent's workplace. Marcosystem is to shape the patterns of characteristics of micro-, meso-, and exosystmes by a given culture or subculture. Particularly, it is about a particular culture or subculture shaping "belief systems, bodies of knowledge, material resources, customs, life-styles, opportunity structures, hazards, and life course options" (P.40). 
Bronfenbrenner's ecological system recognizes the interactions of biological and environmental factors on personal development. It regards the environment as an integrated system, in which there is both direct and indirect influences. In the settings of ecological systems, the biological factors cannot be manipulated to foster children development due to the ethics and technology. While the environmental factors, especially the personally social environment, can be changed to foster personal development. The mass media, one of whose principles is to scale the social justice, can be employed to promote educational justice on migrant children.

\section{Ways of mass media to promote educational justice}

As mentioned earlier, there are two main factors caused the education injustice on migrant children, policies factors and family socio-economic status. Based on the Bronfenbrenner's ecological model, even though these two factors have been identified, it impacts on educational justice on migrant children through multiple levels of systems and settings. Therefore, to explore the means to diminish educational injustice and promote educational justice on migrant children should go through multiple levels of systems and settings surrounded.

\section{Policy factors}

In order to diminish the educational injustice caused by policy factors, the functions of mass media adopted is the surveillance of environment, namely, media supervision. Media supervision means that mass media to supervise the objects through the way of reporting the facts and the news to public and formatting a certain public opinions (Ding, 2002). The social issues the mass media concerns more the public pay more attention on them. When the mass media intensively disseminate one social issue, the social issue will become the public agenda affected the process of policy-making ( $\mathrm{Li}, 2002)$.

The function of mass media for the influence on the policy factors of educational justice is direct impact on the exosystem to indirectly effect the marco- and microsystem. The mass media is suggested to build and guide the public opinions to advocate the settings in the exosystems, such as social organizations and NGOs, to share the responsibilities of the government and provide more social and economic resources for the migrant children $(\mathrm{Li}, 2013)$. The function of supervision can exert influence on the settings of exosystems, especially on the governments, to assist the policy makers to understand the holistic problems the migrant children facing and make justice policies and systems for them.

Through the function of agenda setting, the mass media can focus the government and public attentions on the migrant children and the microsystem of their development. It can force the government understand the educational injustice issues and have immediate reactions toward them. Meanwhile, agenda setting can motive people from higher social classes to help the migrant family and provide more relevant resources for them $(\mathrm{Li}, 2013)$.

\section{Family status}

For the function of transmission of social heritage, the mass media can spread the information and knowledge through diverse ways without limitations of time and space. For those who cannot afford the expensive tuition fee, mass media can provide opportunities for them to receive education. For instance, they can learn from distance learning classes via the internet or television education programmes. This function of mass media tries to replace the function of school in the microsystem to impact migrant children. It also works on impacting other settings in the microsystem to indirectly influence on migrant children and promote educational justice. For instance, mass media can spread relevant information and knowledge to their parents, teachers, and peers. It can changes their perspectives and views on migrant children's education, and devote into educating migrant children.

The function of agenda setting can also be employed in alleviate the adverse impacts of migrant children's lower family status. As mentioned earlier, migrant worker family ranked in the bottom of 
the social class and suffered from the deficit of diverse resources. They have few social resource to help them express their willingness and demands and to protect their rights. Definitely, they were deprived the discourse right and had been stayed in the circumstance of aphasic state for a long time (Chen \& Chen, 2012). In order to change this adverse circumstance and promote the educational justice to migrant children, mass media can worked as a channel to assist migrant children and their families to express their needs and rights, such as informing the public policies, guaranteeing people's civic rights, and providing the discourse right back to the migrant workers and their children on educational justice ( $\mathrm{Li}, 2013)$. This change comes from the influence and functions of mass media itself and works in exosystem of migrant children.

\section{Conclusion}

Central to the principles of the harmonious society, every member has the equal rights access to diverse resources. So does in education. Due to the imbalance of the development of society and economics, children from migrant worker families suffer from the educational injustice, which is the regarded as a new and serious problem in society. Mass media, which becomes much more powerful, can be fully suggest to be employed to enable the voice of migrant children be heard and change the situation of educational injustice through its social functions.

This paper tried to identified the issue of educational justice on migrant children and explore the ways to promote educational justice through the social functions of mass media. Lasswell's three functions theory was used to explore the means of promoting educational justice. Bronfenbrenner's ecological model was utilized to demonstrate the directions of influences of mass media on migrant children.

\section{References}

[1] Bronfenbrenner, U. (1994). Ecological models of human development. International Encyclopedia of Education, 3, 2nd. Ed. Oxford: Elsevler.

[2] Chen, H. \& Chen, Y. (2012). He xie shi yu xia xin wen chuan mei dui ruo shi qun ti de guan huai.Chinese Press Modern Property,1,65-67.

[3] Cheng, W. (2013). Jiao yu gong ping yu zhui qiu you zhi liang de jiao yu gong ping fa zhan de ce lve. Social scientists, 3, 104-108.

[4] Ding, B. Q. (2002). Xin wen yu lun jian du san lun. Chinese Journal The Press,5,16-18.

[5] Du, J. H. (2011). Da zhong chuan mei dui gong ping zheng yi de zuo yong ji zhi ji qi bian jie. Chinese Journal Lanzhou,10,192-195.

[6]Lasswell, H. D. (1948). The structure and function of communication in society. The communication of ideas, 37.

[7] Lazarsfeld, P. F. \& Berelson, B., \& Gaudet, H. (2012). The People's Choice: How the Voter Makes Up His Mind in a Presidential Campaign. China Renmin University Press.

[8] Li, B. (2006). Chuan bo xue yin lun. Xin Hua Press.

[9] Li, L. (2003) .Chuan bo xue li lun yu wu shi. Sichuan People Press.

[10] Li, Y. (2013) .Da zong chuan mei dui liu dong ren kou zi nv yi wu jiao yu wen ti de yu lun gou jian yu jian ce. Chinese Journal Hunan Social Science, 2,228-230.

[11] Liu, H. Z. (2007). She hui jie ceng fen hua yu gao deng jiao yu ji hui jun deng. Chinese Journal Bejing Normal University (Social Science), 1, 20. 
[12] Liu, F.X.(2005).Shi chang tiao jian xia de jiao yu gong ping:wen ti yu zhi du an pai. Chinese Journal Bejing Normal University (Social Science), 1, 23-29.

[13] Long, A.B..\& Fan,W.(2013). Wo guo jiao yu gong ping yan jiu de xian zhuang ji te dian. Modern Education Management, 1, 16-21.

[14] Wang, W.Y. (2005). Bu tong she hui jie ceng zi nv gao deng jiao yu ru xue ji hui cha yi de yan jiu. Chinese Journal Public Education Research, 4, 55-62.

[15] Wei, H. (2011). Lun xin mei tis hi dai wang luo yu lun jian du yu she hui gong zheng. Chinese Press News World,9, 276-277.

[16] Wei, X. F. (2011). Xian jie duan wo guo jiao yu gong ping yan jiu. Dissertation of master researc

[17] Zhong W.Y. (2013). Jiao yu gong ping zhi qian xi. Chinese Journal Nanchang Education College,28 (11), 127-128. 